Semiotic scaffolding of the social self in reflexivity and friendship

Emmeche, Claus

Published in:

Biosemiotics

DOI:

10.1007/s12304-014-9221-0

Publication date:

2015

Citation for published version (APA):

Emmeche, C. (2015). Semiotic scaffolding of the social self in reflexivity and friendship. Biosemiotics, 8(2), 275289. [10.1007/s12304-014-9221-0]. https://doi.org/10.1007/s12304-014-9221-0 


\title{
Semiotic Scaffolding of the Social Self in Reflexivity and Friendship
}

\author{
Claus Emmeche
}

Received: 21 September 2014 / Accepted: 21 October 2014 / Published online: 8 November 2014 (C) Springer Science+Business Media Dordrecht 2014

\begin{abstract}
The individual and social formation of a human self, from its emergence in early childhood through adolescence to adult life, has been described within philosophy, psychology and sociology as a product of developmental and social processes mediating a linguistic and social world. Semiotic scaffolding is a multi-level phenomenon. Focusing upon levels of semiosis specific to humans, the formation of the personal self and the role of friendship and similar interpersonal relations in this process is explored through Aristotle's classical idea of the friend as 'another self', and sociologist Margaret Archer's empirical and theoretical work on the interplay between individual subjectivity, social structure and interpersonal relations in a dynamics of human agency. It is shown that although processes of reflexivity and friendship can indeed be seen as instances of semiotic scaffolding of the emerging self, such processes are heterogeneous and contingent upon different modes of reflexivity.
\end{abstract}

Keywords Self · Semiotic scaffolding $\cdot$ Peirce $\cdot$ Archer $\cdot$ Friendship $\cdot$ Reflexivity

\section{Introduction}

Semiotic scaffolding can be seen as enabling processes of sign action unfolding at several levels of organization, focusing energy flow and agency of the system or subsystem upon a constrained repertoire of possibilities, thus guiding the system's behaviour to follow a more definite sequence of events (cf. Hoffmeyer 2007; 2014).

C. Emmeche $(\bowtie)$

Center for the Philosophy of Nature and Science Studies (CPNSS), Department of Science

Education (IND), University of Copenhagen,

CPNSS, IND, Øster Voldgade 3,

DK-1350 Copenhagen K, Denmark

e-mail: cemmeche@ind.ku.dk 
Before we discuss levels specific to humans, a few comments will be made about scaffolding in general. At all levels, scaffolding serves to stabilize the embodied self of the living system, and this also applies to the most basic biological level of single organisms. Self-maintenance and self-assembly, as common biological terms, refer to processes that are directly or indirectly mediated by the basic sign action of the system. Hence, from the biosemiotic point of view, calling a single cell an organism and stipulating that there is a self of the system, points to the existence of some form of semiotic scaffolding as necessary for the continuous self-organizing processes of metabolism and reproduction. In the case of Earthly life, this is the existence of genetic information remembering and representing specific sequences of amino acids that can self-assemble into e.g., functional enzymes. It is well known that the self-reproduction of such a complex system as a single cell demands more than the aggregated self-assembly of large biomolecules; it needs a coherent representational system, having both 'dynamic'-analogical and 'symbolic'-digital aspects. This condition may be generalized to higher and more complex embodiments of life, although the scaffolding processes are different here.

Thus, a biosemiotic and organicist account of embodiment (cf. Emmeche 2007) must distinguish between a plurality of emergent levels, such as

(a) biological or 'vegetative' embodiment found in all (uni- or multicellular) living systems, enabling self-organizing processes like metabolism and homeostasis, scaffolded by the genetic and epigenetic systems forming a plurality of biocodes;

(b) animate embodiment, that is embedded within (and yet in its organizing principles transcends) the vegetative one as emergent upon it, and realizing full blown functional circles of motor- and perception-processes, enabling fine-tuned selfmovement directed by animate intentionality and scaffolded by various neural representational systems;

(c) anthropic embodiment of the human animal (again presupposing the former levels as its emergent basis) generating sociocultural groups of humans with specific norm systems enabling extensive collaboration, learning-based flexibility, and production of material as well as intangible cultural artifacts (like tools and narratives), all scaffolded by language as a particular system of communication and cognition that again catalyzes the emergence of reflexivity as a mediator between a personal self (as a part of human agency) and socio-cultural structure; and

(d) societal embodiment as an elaboration of the anthropic one, embedding culturespecific ways of living a human life within larger institutional-organizational settings of functionally differentiated social systems such as state, army, market, industry, a general public, civic organizations, sectors of health, education, knowledge production, technology, communication systems - ultimately a global cosmopolitical sphere.

Implied in this conception of different levels of scaffoldings of embodied life is a recognition of the limited validity of any single model when dealing with multiple levels of organization, and thus also the limited range of biosemiotics as a toolbox for investigating anthropic and societal forms of semiotic scaffoldings. However, 
investigating systemic notions (like emergence, semiosis, agency, structure, scaffolding and embodiment) across various levels, including the higher ones, may help to develop and refine such notions, to make their use more precise, also at more basic levels.

This article will investigate the hypothesis that friendship (or similar interpersonal relations) can act as a semiotic scaffolding for the development or individuation of a personal self at the levels of anthropic and societal embodiment. This will bring up the role of reflexivity and its connection with friendship. Although the processes involved here are not described in terms of biology, this does not mean that biosemiotics cannot inspire a relational approach, which is highly relevant. Several conceptions of the self within psychology and social psychology have underscored the social nature of the human self, seen as a dynamic product of developmental and social processes of construction, interaction, and internalization of a linguistic and social world that form the emerging self from early childhood through adolescence and adult life. Such processes are semiotic in nature, but have rarely been analyzed as such. We will explore how semiotic scaffolding at the level of the self helps to provide an understanding of the cognitive and sociological processes at play, exemplified through reflexivity and friendship as an instance of semiotic scaffolding of the self in the process of individuation.

\section{Friendship as a Relational Phenomenon}

The hypothesis that friendship can act as a semiotic scaffolding for the development of a personal self in humans derives from two sources of inspiration, biosemiotics within a systems perspective as just hinted at above by referring to levels of organization, and interdisciplinary studies of friendship, an ongoing research project aimed at elucidating the philosophy and sociology of interdisciplinarity by a slightly peculiar case of a not yet existing field of interdisciplinary studies (i.e., investigating how friendship has been conceived of within different disciplines such as evolutionary biology, anthropology, sociology, political science, philosophy, literature studies, gender studies, etc., and why we have seen so few attempts to approach the phenomenon from interdisciplinary approaches). For the present investigation we will only draw upon work relevant for the specific hypothesis, especially the philosophy and sociology of friendship, and in particular comments upon Aristotle's famous reflections on friendship and the recent work of Margaret S. Archer on the sociology of modernity.

Friendship is relational in several senses. Firstly, it designates a personal relation between two or more persons; secondly, this relationship is dependent upon the nature of the personal subjectivities within that relation and the social and cultural settings constraining and enabling ways to express and realize this relation; and thirdly, the content of the relationship connects to the inner and outer lives of the persons involved, their concerns, experiences and various projects, shared or separate. Fourthly, those involved may or may not relate to this relationship in direct or indirect 
ways and reflect upon its bearings on their overall concerns and life projects. In that sense, the selves of the individuals are directly implicated by the relationship, and the friendship may at least as a possibility appear to be an extension of the relational and dialogic nature of the very self of each person involved. ${ }^{1}$ Fifthly, if the co-created relational goods reflexively become integral to the life-trajectories of those involved, the friendship has emerged as a phenomenon generating its own dynamics in the mediation of person and society.

Starting with Aristotle, philosophy in the West has fostered a series of reflections upon different types of friendship, their moral character, and the essential nature of this relation in its purest form. For instance there has been a long discussion of Aristotle's remarks that a genuine friend is loved for his or her own sake. ${ }^{2}$ It seems to be compatible to a modern view of friendship that loving one's friend in and for himself means to love the person as he is, rather than what he possess or can do for me, the utility or pleasure he confers. It has been argued that this can be seen as a partly descriptive claim about a person's uniqueness and irreplaceability, and partly a normative claim that a friend of the best kind loves the essence of his friend's being, not accidental characteristics like wealth, special talents or useful or pleasant qualities (Stern-Gillett 1995; Lynch 2005). In Aristotle, the descriptive and normative claims are interconnected with his view of what might be called the integrity of a person, because Aristotle associates the self with the intellectual part of a man who is completely integrated and desires the same things with every part of his soul, i.e., his degree of self-control is high. As Lynch (2005: 29) comments, "for Aristotle to like a person for his or her own sake is to like him for his intellect or reason; and since it is reason's function to control and integrate a man's desires and energies in the service of the good, then to like a person consists precisely in liking him for his connection with goodness." Thus liking a person for himself and liking him for his goodness or good character amounts to the same thing. Vicious or weak-willed persons are not regarded by Aristotle as selves in the fullest sense of that word as they are pulled in different directions by their passions and appetites.

\footnotetext{
${ }^{1}$ For dialogism and semiotics, see Petrilli and Ponzio (2005). Relational thinking in biosemiotics has often been inspired by notions specific to the human levels like Kierkegaard's notion of the self that Hoffmeyer (1996: 50) quotes: "But what is the self? The self is a relation that relates to itself, or else it is within the relationship that the relation relates to itself; it is not the Self that is the relationship, but that the relation relates to itself." Hoffmeyer comments that "a human being becomes a 'self' insofar as it can, in a given action or choice context, stand back from the situation and evaluate its own relationship to it. Thus, a "self" presupposes a three-factor relation in which the individual refers both to the situation in which he finds himself and to his own presence in that situation." (ibid.). This capacity is what Archer (see below) terms reflexivity.

2 "a man's best friend is the one who not only wishes him well but wishes it for his own sake (even when nobody will ever know it)", from Lynch (2005: 15-16) quoting Aristotle's Nichomachean Ethics 1167a18b64; the same idea is stressed in Aristotle's Eudemian Ethics (cf. Stern-Gillet 1995: chapter 3). As to the gender issue, Aristotle saw virtue friendship as a (relatively rare) relation between good, wealthy, and virtuous men, and though he did not preclude that if husband and wife are decent, their friendship may be one of virtue, he was not very interested in and had few and inconsistent remarks on women, which should be seen against the backdrop of a socially unequal and patriarchal Greek city state (Baltzly and Eliopoulos 2009). This article assumes a different backdrop and do not use "he or she" all the time.
} 
It is tempting to say that we see here an early attempt to point to rationality (and its dialogic aspect) as a devise for scaffolding the emergence of a mature kind of selfhood.

More important, however, is Aristotle's idea that the friend is like 'another self' (allos autos). ${ }^{3}$ Though opinions differ as to the centrality of this idea for his overall account of friendship 4 it is at least important in its relational aspect. The reflexive relation that individuals have to themselves is here extended to encompass another individual, the friend, and as Stern-Gillet observes, this reflexive notion of selfhood is not just descriptive, as in modern psychological accounts, but to the extent that Aristotelian selfhood is an evaluative, commendatory notion, it is explicitly normative: The self is to be considered as an achievement, namely of a state of equilibrium between various parts of the soul. It becomes an ideal to strive for "but which we may not reach" (ibid., p. 29). Talking about a friend as 'another self' or 'another me' is in no way to allude to a psychological symbiosis or fusion of two minds into one. As 'another self' the friend is still a separate entity and helps an individual without preempting his own rational agency or desire to make choices. Friends help each other not by making choices for each other but by giving greater opportunities for choice and greater means for realizing ends. As Sherman (1993: 104) remarks, these means may include scarce material resources or psychological goods such as support and esteem and confidence in our endeavors, without minimizing the seperatedness of a friend. On Aristotelian grounds also Vernon (2005: 146) emphasizes that friends may share an intensity of feeling for each other, including joys and sorrows, successes or failures, but "they never seek to consume each other or fall in a perpetual embrace."

However, there seems to be a deficiency or difficult tension in Aristotle's account related to his idea that friendship of the best kind is only entered among men who are already virtuous in character and thus self-possessed; that friendship depends upon the self-sufficiency of each of the friends. But if so, what about a genuine motivation for a friendly care for the other person? This has raised suspicions about egoism in Aristotle's account, suspicions that according to Lynch (2005: 45) "might have been undermined had he addressed the process by which an individual might come to regard another and different person as another self". Aristotle does not much to analyze the social tie in itself, just how one's friend is another self (cf. Singer (2009: 98) [1966: 102]). Though left out of his account, in the modern epoch such processes have been subjected to psychological and sociological investigations. So let us leave philosophy for a moment to take a closer look at some of the recent empirical research into those processes that - with some bits of cognitive and emotional work and a little luck - may allow us to be ourselves with others (compare (Little 2000).

\footnotetext{
3 "The decent person, then, has each of these features in relation to himself, and is related to his friend as he is to himself, since the friend is another himself" (Aristotle, Nichomachean Ethics, 1166a29-32, here quoted from Stern-Gillett (1995: 28), other similar quotesibid. and chapter 2 passim). See also the penetrating analysis provided by Pangle (2003).

${ }^{4}$ Grayling (2013: 35) claims it to be overstated and a distortion in subsequent treatments of friendship, but most scholars, including Stern-Gillet, scrutinize its possible interpretation and implications.
} 


\section{Reflexivity and the Self}

We shall focus on parts of the work on reflexivity and modernity by Margaret Archer. Hers is an account of (i) how human reflexivity scaffolds the decisions individuals face concerning their overall life trajectories, both in general, i.e. for all humans throughout cultural history and (ii) specifically how modernity shapes the interaction between agency (individual subjectivity) and social structure and culture, and promotes special forms of reflexivity. We will focus upon (i), her theory of reflexivity that pertains to the above-mentioned anthropic level of embodiment. This theory Archer 2003; 2007 is in part inspired by C. S. Peirce's writings on the dialogic nature of the self, and by Pierpaolo Donati's relational sociology. ${ }^{5}$

Discussing the private conscious life of the social subject, Archer (2003) maintains, as part of a pluralistic ontology, a domain of mental privacy within every conscious human being. This life of the mind with its first-person ontology is not directly accessible to outside inspection, as our internal deliberations need not have behavioral manifestations. But it is not a matter of passively 'looking inward', to see what can be found there in the stream of consciousness; Archer replaces the dubious notion of 'introspection' by a notion of internal conversations. We continually converse with ourselves to find out what we believe, desire, and intend to do. Our reflexivity is causally efficacious, it is a personal power that enables us to be the author of our own projects in society (ibid., p. 34), "we can modify ourselves by reflecting upon what we most care about and how we must accommodate all our other concerns to it" (ibid., p.41). This internal conversation objectively exists, but it has a subjective ontology as subjectivity is its mode of existence. Hence, this first-person perspective is ineradicable, and linked to the development of selfhood: Archer in her previous works drew upon Merleau-Ponty and Piaget to show how a sense of self, as distinct from other objects and other subjects, emerges from our practical relational encounters with the world, again a kind of semiotic scaffolding. It is reflexivity that allows us by monitoring and prioritizing our concerns to acquire a personal identity. Thus in Archer's theory personal reflexivity is the mediator between social structure and social agents. As human agents we have the power to deliberate internally upon what to do in situations that are not of our own making. As part of her empirical research involving qualitative interviews with real people, Archer found that the stances we take - evasive, strategic, or subversive - are differently related to specific modes of reflexivity. Before we consider this, we must ask what precisely is meant by claiming that reflexivity in general has the form of an inner conversation.

\section{The Semiotics of Internal Conversation}

Moving the conception of reflexive knowledge of the self from an empiricist paradigm of introspection (known from nineteenth century philosophy and

\footnotetext{
${ }^{5}$ Interestingly, Donati uses the example of friendship in one of his attempts to explicate the emergent reality of social relations and the relational character of social reality Donati (2011: 65f).
} 
psychology of John Stuart Mill, Wilhelm Wundt, and E. B. Titchner) to a realist ${ }^{6}$ one of internal conversation (Archer 2003) takes us through three stages, represented by the contributions of W. James, C.S. Peirce, and G.H. Mead, corresponding to three ways of balancing between structure and agency in modeling reflexivity.

William James' work is seen by Archer as a tentative departure from a purely observational model of self-knowledge. Although James became known as a defender of introspection as a method of psychology (looking into your own minds and report what you find), he was also preoccupied with thinking as a real process and began to recognize deficiencies in the observational model. To 'see' anything, that something must be clearly visible and this is not so with many of our thoughts that can be vague, cloudy, or appearing as brief premonitions. To maintain an analogy between on the one hand, 'grasping a thought' within 'the stream of consciousness' and, on the other hand, 'looking' inwards, is misplaced. Even if we had an 'inward eye' much of what takes place inside would be invisible to it. Memory (or introspection-as-retrospection) as a substitute for the 'inward eye' does not work either, as memory can seldom accurately reproduce the very act of thinking upon an object: "The mass of our thinking vanishes for ever, beyond the hope of recovery" as James wrote. ${ }^{7}$ He then presented a rudimentary shift to an alternative model, one of 'listening' to ourselves. Thinking is rather a matter of interior speaking and listening. Internal articulation takes time, and we listen to ourselves as we move through the internal utterance in an active process of self-monitoring. This intra-active process consists in moment-by-moment deliberation, evaluation and selection. By these elements - thought as internal speech, listening to ourselves as we phrase our thoughts, and the appreciation that the articulation of what we mean entails self-monitoring and a kind of sifting mechanism - James had actually conceptualized thought as an inner monologue, as Archer calls it (ibid., p. 64) but did not take the last step to conceptualize this mechanism as dialogical. He did not conceptualize the inner dialogue at all, but still he pointed to an alternative conception of reflexivity that acknowledged its interiority, its subjective ontology, and its causal efficacy, as also Peirce did.

Archer places C.S. Peirce as the fulcrum between James' traditional individualism and Mead's over-socialized conception of humankind and tendency to reduce away the psyche as an emergent causal power. Peirce succeeded in offering a balance between our external life in society and our internal life of the mind. For him, to be human is to exist in a tension between solitude and solidarity. ${ }^{8}$ Archer phrases some of his ideas about the inner dialogue in the terminology of social realism, which is compatible with the terminology of semiotics that he used. Peirce thought the reflexivity to be quintessentially dialogic, a matter of speaking, listening and responding to oneself, a sign phenomenon of course, but how exactly does such a process take place? Briefly (and more elaborated in Archer (2003: 64-78), if thought is really conversation, it must employ language and logic, which are 'public media' as Archer

\footnotetext{
${ }^{6}$ Archer conceives her theory in the tradition of critical realism. I consider her notion of reflexivity as internal conversation to be fully consistent with semiotics.

${ }^{7}$ p. 276 in The Principles of Psychology, here quoted from Archer (2003: 62).

${ }^{8}$ Also Petrilli-and-Ponzio (2005: 51, cf. p. 55-56) quote this expression from Colapietro, see next note.
} 
notes. But this does not undermine the privacy of thought, and Archer concurs with the Peirce scholar Vincent Colapietro in explaining that our reliance upon the public media of language and the public domain of culture can be upheld without this determining what we do with it. "When I enter into the inner world, I take with me the booty from my exploits in the outer world, such things as my native language, any other languages I might know, a boundless number of visual forms, numerical systems and so on. The more booty I take to that secret hiding place, the more spacious that hiding place becomes", "the power and wealth of signs that I borrow from others and create for myself determine the dimension of my inwardness". ${ }^{9}$ Obviously, this is a process of learning. Only gradually children start to refrain from spontaneous action and begin to stop and think before acting. Peirce thus enables a developmental account of how interiority emerges from externality and how a private domain is elaborated from the objective affordances (or scaffoldings) of language, to endow the inner conversation with causal powers. As Archer explains (ibid., p. 70f), drawing upon Peirce's stratified view of the self, as our extrinsic causal powers are rooted in the internal conversation, this is a form of semiosis. In this process a part of the internal dialogue (in its aspect of a past 'Me' or a 'critical self' as Peirce would say) functions as Object, the resulting modified self (an aspect of the self that Archer calls the present 'I') as Sign, and the future society as an Interpretant upon which the effect of the sign is exerted (together with a transformed 'You' above to move down the time-line and assume the position of the acting ' $\mathrm{I}$ '). These two successive moments of the internal conversation, concerned with the 'Me'-'I' and the 'I'-'You' relation, are overlapping and intertwined and should be seen more as analytical devices, "because I only talk to myself and the internal conversation is not between three reified persons inside me", they are aspects of the one person (ibid., p. 75). Neither Peirce nor Mead gave concrete examples of the inner dialogue to illustrate their theoretical ideas, but Archer does so (2003, chap. 3) to reclaim its reality and (also in Archer 2007; 2012) investigate its varieties.

In the same way, as for Archer Peirce constitutes the high point in previous theorizing on internal dialogue, so also for the present hypothesis about semiotic scaffolding of the self, is his remarks about self-control and semiosis highly relevant. We will therefore just briefly refer to George Herbert Mead, whose name strangely has become synonymous with 'internal conversation' in sociology. In Archer's critical evaluation of Mead's theory, it represents an over-socialization of the internal conversation in the sense of Mead being an uncompromising externalist. In Mead, society takes over internal conversation, which is stripped of interiority, subjectivity and personal causal efficacy: The private domain of thought is absented, because thinking is seen as the same as talking to other people, or as simply a phase of a social act. A subjective ontology of thought is denied, as individual thinking becomes just a part of society's conversation, not a conversation with oneself, but with society, in the form of the 'generalized other' in Mead's terminology. If internal conversation has any social powers they are not attributable to something personal, but constitute ${ }^{9}$ p. $115-16$ in V. Colapietro, Peirce's Approach to the Self: A Semiotic Perspective on Human Subjectivity
(Albany, N.Y.: State University Press, 1989), here quoted from Archer (2003: 69). 
the powers of society working through the medium of the individual. Another way to state Archer's point is that in talking about the 'social self' (as in this essay's title) we should not commit 'the central conflation' of positing a self with no subjective autonomy, as if completely 'constituted by' (or remainderless socialized into) the structure of its society. This reductionist tendency would deny its emergent personal powers, just as genetic reductionism denies the emergent powers of a self-moving animal or a self-organizing developmental system like an organism in which the genome only works as one of many scaffolding devices (Hoffmeyer 2014).

\section{The Modes of Reflexivity}

Already in her in-depth exploratory study (Archer 2003) of twenty interviewees, selected to have as diverse a group as possible with regard to class, age, gender and occupation, Archer found four different modes of reflexivity, as later substantiated by her larger studies of a cross-section of a local population in Coventry (Archer 2007) and a longitudinal study of university students as entrants and close to graduation after three years (Archer 2012). The four modes emerged from qualitative data elucidating the inner mechanisms of thought on what is of most concern to the subjects, according to their own definitions. Finding of different modes appear surprising if we typically believe that other persons exercise reflexivity in much the same way as oneself does (2003: 157), and indeed, social theorizing in general has regarded reflexivity as a homogeneous phenomenon. As it is difficult in a short text to compress the rich feel for these modes and their practitioners conveyed by the research reported in her trilogy, we will just indicate their most salient features. We can all exercise each of these four modes, and do so in various situations, but Archer's research demonstrates that a vast majority of individuals can be characterized by one single mode as the dominant form when it comes to major decisions about making their way through the world. These modes are not a fixed psychological faculty, but (as semiotic scaffolding in general) an emergent and relational property, which is open to shifts.

Communicative reflexivity is a mode in which the internal conversations need to be confirmed and completed by others before they lead to action. The communicative reflexives are 'working at staying put' in a contextual continuity with family and friends, who are their most important concerns and whom they value and trust. They doubt that internal conversations alone would lead them in the right direction, and have a high awareness of the contingency of the internal life of the mind in its forms of flights of fancy. They have plenty of external dialogue partners around, related to a low geographical and social mobility, and they are characterized by a smooth dovetailing of their multiple concerns, e.g., work and leisure, most often prioritizing family and friends, making for a modus vivendi with a high degree of contentment, and thus often replicating the social situation of their background. They have an actively evasive strategy of rejecting opportunities that would threaten the contextual continuity of their lives. As a mode of deliberation the exercise of communicative reflexivity depends upon turning to similar others: "The better the interpersonal relationships involved, the broader the self-disclosure and the greater the permeability of 
the self to the surrounding context" (2003: 209). Their 'thought and talk' mode can be said to be a dual intrinsic and extrinsic dialogical scaffolding of the self.

Autonomous reflexivity is characterized by self-contained internal conversations that directly lead to action. The deliberations of the autonomous reflexives are selfsufficient as they believe that no other than themselves can know exactly what they value or what projects to pursue. Being confident in the outcomes of their deliberations they take responsibility also for its failures, the errors and the ensuing self-diagnosed and self-directed corrections and revisions (reminding us that all reflection is fallible and potentially self-correcting). The autonomous reflexives are 'upward and outward bound', willing to move away from their initial context of involuntary placement, thus often having stories of contextual discontinuity. They are likely to activate social constraints as well as enablements. As the communicative reflexives their dovetailing of concerns are unproblematic, but typically it is work or career that is their primary concern. Being individualists they use self-disciplined monitoring in their active engagement, to competitively adapt to new situational opportunities, taking a strategic stance. Through the inner conversation they "begin to anticipate the constraints that their refined projects are likely to encounter and the enablements that may assist them" (2003: 253) and they often become more expert in understanding the workings of their society.

Meta-reflexivity is a mode in which the internal dialogues critically evaluate previous inner dialogues and are critical about action in society. In its core it simply entails being reflexive about one's own thinking, which every normal human practice, at least occasion. As a characteristic mode, however, it is more about the self than about the agent's external actions. Archer (2003: 256) notes that the interviews she conducted with the meta-reflexives' were the most difficult to transcribe "because of their use of subordinate clauses, their false starts, reformulations, the interjection of clarifications and their general ruminative form". Meta-reflexives are preoccupied with interrogating their own motives and reactions. They share the contextual discontinuity with the autonomous reflexives, but no available context is such that they can embrace it uncritically and lastingly: The meta-reflexives are 'moving on'. As idealists they are amongst society's critics, taking a subversive stance, but their ideals also make them critical about themselves as persons and of the lives they lead. This makes it difficult for them to dovetail their concerns. They want all their different involvements in life to be aligned with a coherent harmonious ideal, which is the ultimate concern they are committed to, but these involvements keep slipping out of alignment. They constantly evaluate their situation in the light of their concerns and not vice versa. If a situation is too disparate from their ideals, they quit, which makes for a certain 'biographical volativity’ (2003: 293).

Fractured reflexivity is a cluster of modes where internal conversations cannot lead to purposeful courses of action, but rather intensify personal distress and disorientation resulting in expressive action. In contrast to the three modes above, they are not active agents, but stuck in agential passivity. These subjects can be $(i)$ 'impeded', meaning that they cannot develop one of the other modes to the extent that it would 
help them to scaffold an active stance towards society. Or ( $i i)$ they can be 'displaced' from one of the modes they have previously exercised but cannot use anymore, due to e.g. unemployment or health problems. This involuntary situation make them rejectors regarding their natal background. Finally (iii) there is a category of 'near non-reflexives' who are even less capable to exercise reflexivity, and who barely hold internal conversations. Common to all fractured reflexives is that they do not appear purposive about their life situation, or as if learning from their experience. They are disoriented about their concerns, about how best to act to realize their priorities, or both. Their self-talk is primarily expressive, leading to intensify affect - feeling distressed about their situation - and thus, internal conversations are often shunned; it cannot scaffold a constructive stance to the situation. ${ }^{10}$

\section{The Modes of Friendship in Archer's Research}

Seen from the perspective of Archer's research, our hypothesis that friendship can act as a semiotic scaffolding for individuation of the self and identity formation leads to the inference that the ways in which friendship (and the friend as 'another self') scaffolds this process will take different forms depending upon the mode of reflexivity involved. Though Archer does not use the notion of scaffolding, this inference is supported by her latest work (Archer 2012) that pays considerable attention to friendship. To see how the modes of reflexivity relate to friendship we can take departure in her scheme reproduced in Fig. 1.

The 'home friends' are network of friends that the students interviewed by Archer (2012) know from their natal background, while 'new friends' denote friends made after enrolling in the university. Of interest here is whether friends are continuous and complementary with the individual's natal background or at variance with it, and in general what kinds of relationalities characterize the friendships of the different reflexive modalities.

The communicative reflexives tried to retain their home friends that acted as interlocutors in their 'thought and talk' mode, but as that often proved practically challenging having moved to a distant university, they seek out new friendship provided by 'similars and familiars', i.e., people who can understand and enter into the subject's concerns and preoccupations to such an extent that they can complete and confirm their friend's tentative thoughts by their talk together. They seek multifaceted friendships, covering a plurality of dimensions. Presumably it is for this group that friendship is most important as a semiotic scaffolding for the construction of a coherent and active self with a clear priority of concerns and pursuits in life. However, this reflexive mode may also circumscribe some mental activities that fall under the rubric of internal conversation, especially the uninhibited exercise of imagination,

\footnotetext{
${ }^{10}$ Though some may be tempted to explain severely fractured reflexivity by individual psychopathology, Archer abstains from direct psychological explanations. Affective disorders such as depression or anxiety are often the effects rather than the causes of the situations in which the fractured reflexives find themselves. Far from all are affliced by such disorders, and fractured reflexivity is a broader phenomenon Archer (2003: 303f).
} 


\begin{tabular}{|c|c|c|}
\hline Dominant mode of reflexivity & $\begin{array}{c}\text { Relations with } \\
\text { home friends }\end{array}$ & $\begin{array}{c}\text { Relations with new } \\
\text { friends based on }\end{array}$ \\
\hline Communicative Reflexives & Retention & Commonalities \\
\hline Autonomous Reflexives & Selection & Interest-based \\
\hline Meta-Reflexives & Rejection & Value-based \\
\hline Fractured Reflexives & Absence & Dependency \\
\hline
\end{tabular}

Fig. 1 Modes of reflexivity and friendship patterns (from Archer (2012, p. 148 and 293)

unrestrained by the reality principle, or what Peirce called the play of musement. This use of imagination may help extent the horizon beyond one's everyday context and initiate a process of discernment about endorsing bolder projects in life, and Archer (2007: 270-275) sees this attenuated use as partly explaining the social immobility of many communicative reflexives.

Upon entering the university, the autonomous reflexives directly faced what they saw as a need to select and keep just few of their home friends and shed the rest of their previous network of friends. New friendships were not their highest priority and these were not characterized by great interpersonal intensity but were often unifaceted, i.e., linked to different specific activities and valued because they promote common pursuits and enhance their enjoyment. To them, dependency in friendship would be "anything but repugnant" as Archer (2012: 179) comments. Typical of autonomous reflexives is a greater difference between their approach to friendship, which is often controlled and instrumental, but seen as a pleasant form of diversion, and their approach to love or becoming a couple, that inevitable demands a fuller personal commitment and self-investment that may compromise or deflect their earlier dovetailing of concerns. Development of this more serious kind of relationship may lead to a further filtering of the friendship they make with others. Being the individualists they are, friendship hardly scaffolds their identity; the semiotic scaffolding primarily takes place as an internal conversation, but autonomous reflexives may indeed approach love as the formation of a 'we' oriented towards a common project with emergent relational goods, and not just as a partnership of two compromising individuals (ibid.). ${ }^{11}$ That the meta-reflexives are interest-directed is reflected in the durable friendship they may form. Archer discovered a general pattern of

\footnotetext{
${ }^{11}$ (Archer 2012: 167f) notes that for the generation of autonomous reflexives, it is often the absence of relational goods from their parents, rather than the presence of relational evils, that is influential: "autonomous subjects are parented by two individuals rather than by a couple". Being a couple is seen as an emergent relational phenomenon orienting both partners to their relationship and its products. Her distinction, based upon a notion of 'relational reflexivity' (ibid., p. 96-99, 115-124; see also (Donati 2011), between a couple producing relational goods (such as love, reliance, caring and trust), and a mere partnership with no development of 'we-ness' or collaborative decision-making, could as well be applied to different kinds of long-term multifaceted friendship, a topic Archer did not investigate in depth.
} 
attenuation in their home friends as they share less and less in common over the three years as undergraduates. "This proves to be the case even for friends from the natal background who do support the same 'cause' but are felt not to have moved on in their thinking." (Archer 2012: 222). They form new friendships on the basis of their personal, vocational and value-based concerns, and these relations are not allowed to deflect them from their essential commitments. However, "what they cannot understand is that not all are like them and their friends are self-selected from those who are equally involved" in their own spheres of interest (ibid., p. 223). Being work-driven and interest-led, their selection of close friends could be within a context of organizations campaigning for some cause. One might think that they seek out friendship for scaffolding their deliberations about their various projects. However, in this regard they seem to be similar to the autonomous reflexives, not in sharing their instrumental rationality (as the meta-reflexives tend to be value rational agents) but in subordinating friendship almost instrumentally to their ultimate concern. This eventually leaves some ambivalence and uncertainty, as one student said, "I sometimes wonder how important I am as a friend or am I just another hand to help out?" (in a campaign; ibid., p. 225). The material presented by Archer so far does not indicate exactly how friendship may scaffold the deliberation and prioritization of the concerns of the meta-reflexives. ${ }^{12}$

The fractured reflexives, defined by the incapacity for various reasons to let internal dialogue lead to purposeful action, often shed their home friends (if any) when translocating to a university, being 'rejecters' of their natal background. We should remember that they may not be lacking in insight but remain trapped in agential passivity. The new friends they eventually make often become especially influential not just because they have a clear field for new relations, but also because such friends have a high potential for facilitating a move out of passivity, encouraging themselves to make the necessary selections. This make their friendships a potentially strong scaffolding device as we saw with the communicative reflexives; it becomes directly helpful "because then you can actually do it if you have someone to tell you that you can" as one subject related (Archer 2012: 266). This may also make them quite dependent upon someone taking them under their wing. Another challenge is that their 'fracturing', being relational in origin, can impinge on their ability to form new relationships, as this capacity may be just as impaired as their reflexivity is impeded.

\footnotetext{
${ }^{12}$ Further insights may be gained from the independent work of political psychologist Graham Little (2000), whose category of "communicating friendship" (of people coming from what he calls "special families") has some affinity to Archer's meta-reflexives, just as his category of "social friendship" (of individuals from "strong families") are partly similar to the autonomous reflexives, and his "familiar friendship" (often of persons from "good families") share similarities with Archer's communicative reflexives. Though we are only talking about similarities - these notions are not completely parallel - the existence of some affinity is interesting. Little may give us a clue as to the scaffolding function of friendship for the meta-reflexives, especially those kinds of friendship which is "an attempt to link the social emphasis on achieving in society with the familiar emphasis on being content with yourself, hoping to avoid the narrowness and conformity of one and the sentimentality and dependence of the other" Little (2000: 180)
} 


\section{Concluding Remarks}

The findings of our preliminary exploration can now be summarized: Friendship can act through dialogical semiosis to scaffold the formation of an active self with an identity defining a series of pursuits and concerns. It is not a universal condition for individuation, as the scaffolding may also work through a primarily internal process of reflexive conversation. Semiotic scaffolding through friendship may be most typical of what Aristotle and the classical authors called excellent or good friendship, where you care non-instrumentally for the friend for his or her own sake, the care is reciprocated, and the friends are 'communicating' (Little 2000) about a plurality of their concerns of life. This scaffolding is extensive for individuals practicing communicative reflexivity, and to a lesser extent (and depending upon other circumstances) for the autonomous reflexives, the meta-reflexives and the fractured reflexives. More research is needed to elucidate specifically how this scaffolding is realized through dialogical semiosis, and by which mechanisms a friendship may move from being a relational phenomenon only in the first four senses mentioned above, to also being an emergent relational good, reflexively recognized as such by the individuals involved, thus integrating their relationship as a common goal among their other projects in life. This 'relational solution' (Archer 2012: 112ff) is something very real, achieved by the agents themselves, in addition to being a perspective developed in sociology and semiotics for describing what is going on. The emergent relational goods of friendship may also be understood from the perspective of shared intentions and plural agency; notions developed especially in Bennett W. Helm's recent philosophy of friendship (Helm 2010) that are highly relevant and to some extent complementary to Archer's research, in ways that deserve a longer text to discuss.

On the level of anthropic embodiment there are no logical or semiotic reasons why friendship in this more emphatic sense as an explicit relational good (with a sense of plural or joint agency) could not emerge even among practitioners of those other (non-communicative) modes of reflexivity, although Archer's research indicates that such instances may be rare. On the societal level of embodiment, however, where the impact of institutions are omnipresent, one can better understand why friendship as "a kind of institutionalized non-institution" (Paine 1974: 128) is susceptible to become less recognized as a relational good in itself, and more perceived as simply a 'private' matter outside the sphere of politics or institutional policies, and thus highly contingent upon other relationships (cf. Osterberg 2010).

\footnotetext{
Acknowledgments The research was financed by the University of Copenhagen and the Danish Velux Foundation's research programme Humanomics (grant no. 437810). Thanks to David Budtz Pedersen, Frederik Stjernfelt, Simo Køppe and members of the Humanomics research group for good suggestions. Thanks to Maria Eunice Quilici Gonzalez, Mariana C. Broens and Maria José Vicentini Jorente for inspiration and thoughts and for inviting me to the VIII International Conference of Information, Knowledge and Action (EIICA) and the VII International Coloquium of Philosophy of Mind (CIFM) in Marilia, São Paulo State, December 2013. Thanks are also due to Jon Nixon, Susan Haack, Henrik Zinkernagel, Rasmus Grønfeldt Winther, Theresa Schilhab, Wendy Wheeler, and Di Ponti for comments, help, critique and support, and the same goes for my old biosemiotic friends.
} 


\section{References}

Archer, M.S. (2003). Structure, Agency and the Internal Conversation. Cambridge: Cambridge University Press.

Archer, M.S. (2007). Making our Way through the World. Human Reflexivity and Social Mobility: Cambridge: Cambridge University Press.

Archer, M.S. (2012). The Reflexive Imperative in Late Modernity. Cambridge: Cambridge University Press.

Baltzly, D., \& Eliopoulos, N. (2009). The classical ideal of friendship. In Caine, B. (Ed.) Friendship: A History, (pp. 1-64). London: Equinox.

Donati, P. (2011). Relational Sociology. A new paradigm for the social sciences. London: Routledge.

Emmeche, C. (2007). A biosemiotic note on organisms, animals, machines, cyborgs, and the quasiautonomous robots. Pragmatics \& Cognition, 15(3), 455-483.

Grayling, A.C. (2013). Friendship. New Haven \& London: Yale University Press.

Helm, B.W. (2010). Love, Friendship, and the Self: Intimacy, Identification, and the Social Nature of Persons: Oxford: Oxford University Press.

Hoffmeyer, J. (2006). Signs of Meaning in the Universe. Bloomington: Indiana University Press.

Hoffmeyer, J. (2007). Semiotic Scaffolding of Living Systems. In Barbieri, M. (Ed.) Introduction to Biosemiotics, (pp. 149-166): Dordrecht: Springer.

Hoffmeyer, J. (2014). The semiome: From genetic to semiotic scaffolding. Semiotica, 198, 11-31.

Little, G. (2000). Friendship: being ourselves with others. Melbourne: Scribe Publications. (A minor revision of the 1st ed., Melbourne: Text Publishing, 1993).

Lynch, S. (2005). Philosophy and Friendship. Edinburgh: Edinburgh University Press.

Österberg, E. (2010). Friendship and Love, Ethics and Politics. Studies in the Medieval and Early Modern History: Budapest \&amp; New York: Central European University Press.

Paine, R. (1974). An exploratory analysis in 'middle-class' culture. In Leyton, E. (Ed.) The Compact. Selected Dimensions of Friendship, (pp. 117-137): Institute of Social and Economic Research, Memorial University of Newfoundland: University of Toronto Press.

Pangle, L.S. (2003). Aristotle and the Philosophy of Friendship. Cambridge: Cambridge University Press. Petrilli, S., \& Ponzio, A. (2005). Semiotics Unbounded. Torento: University of Torento Press.

Sherman, N. (1993). Aristotle on the shared life. In Badwhar, N.K. (Ed.) Friendship. A Philosophical Reader, (pp. 91-107): Ithaca \&amp; London: Cornell University Press.

Singer, I. (2009). The Nature of Love Vol. 1: Cambridge, Mass.: MIT Press [= The Nature of Love.Plato to Luther.New York: Random House, 1965].

Stern-Gillett, S. (1995). Aristotle's Philosophy of Friendship. New York: State University of New York Press.

Vernon, M. (2005). The Philosophy of Friendship. Houndmills \& New York: Palgrave Macmillan. 